\title{
Examination of weekly mammary parenchymal area by ultrasound, mammary mass, and composition in Holstein heifers reared on 1 of 3 diets from birth to 2 months of age
}

\author{
K. M. Esselburn, ${ }^{*}$ T. M. Hill, † H. G. Bateman II, $\dagger^{1}$ F. L. Fluharty, ${ }^{*}$ S. J. Moeller,ł K. M. O’Diam, ${ }^{*}$ \\ and K. M. Daniels ${ }^{\star 2,3}$ \\ *Department of Animal Sciences, The Ohio State University, Ohio Agricultural Research and Development Center, Wooster 44691 \\ †Nurture Research Center, Provimi North America, Brookville, OH 45309 \\ ‡Department of Animal Sciences, The Ohio State University, Columbus 43210
}

\begin{abstract}
Monitoring in vivo growth of mammary parenchyma (PAR) has historically been difficult, necessitating slaughter studies to measure PAR quantity. Advances in ultrasound (US) technology warrant revisiting its use as a noninvasive tool to monitor PAR growth in vivo. The level of nutrient intake during the first 2 mo of life may affect measures of mammary growth and composition. Objectives were to examine the utility of US as an in vivo tool to quantify PAR cross-sectional area in Holstein heifers reared on 1 of 3 diets from birth to 2 mo of age, assessing potential dietary effects; assess the relationships between weekly US measurements, teat length, manual palpation of PAR scores, and PAR mass at 2 mo of age; and examine mammary composition in experimental animals. Holstein heifers $(\mathrm{n}=24 ; 41$ $\pm 1 \mathrm{~kg}$ initial body weight) from a single farm were randomly assigned to 1 of 3 milk replacers that differed in source and amount of fat. Milk replacer was fed at $660 \mathrm{~g}$ of dry matter/d until weaning at $42 \mathrm{~d}$. Heifers had ad libitum access to a common calf starter $(20 \%$ crude protein) and water for the duration of the 56-d trial. Teat length and palpation scores were obtained weekly. A real-time B-mode US with a $7.5-\mathrm{MHz}$ convex probe was used to examine 2-dimensional PAR area in all 4 glands of heifers once weekly from 2 to $3 \mathrm{~d}$ of age to harvest at $56 \mathrm{~d}$. The left front and left rear glands were also examined by US $24 \mathrm{~h}$ postharvest to validate final US measurements, and then bisected to produce a sagittal plane view of PAR for comparison with US images. Mass and composition of mammary gland tissue were determined at $8 \mathrm{wk}$ using standard methodology.
\end{abstract}

\footnotetext{
Received November 3, 2014.

Accepted April 9, 2015.

${ }^{1}$ Deceased (January 2015).

${ }^{2}$ Corresponding author: danielsk@vt.edu

${ }^{3}$ Current address: 175 West Campus Drive, 2070 Litton-Reaves Hall, Virginia Tech, Blacksburg 24061.
}

Over the course of this 8-wk trial, average teat length increased from 11 to $17 \mathrm{~mm}$. The PAR area started small $\left(6.6 \pm 3.2 \mathrm{~mm}^{2}\right.$ per gland $)$ and increased to 42.1 $\pm 2.5 \mathrm{~mm}^{2}$ per gland by the end of the trial. As anticipated, based on measurements obtained at slaughter, US measurements were more related to amount of PAR $(\mathrm{r}=0.74)$ than either teat length $(\mathrm{r}=0.34)$ or palpation scoring $(\mathrm{r}=0.63)$. Importantly, US is quantitative, whereas palpation scoring is subjective. Diet did not affect mass or composition of PAR in young heifers; total udder PAR mass averaged $1.40 \pm 0.80 \mathrm{~g}$. In conclusion, we showed that in heifers younger than 2 mo of age, obtaining weekly PAR measurements via ultrasound is an effective quantitative tool for measuring changes in PAR area in vivo. Future studies may incorporate and expand upon the methods developed here to determine what quantitative evaluation of PAR in young heifers can reveal about milk production capacity.

Key words: dairy heifer, mammary, ultrasound

\section{INTRODUCTION}

Initial growth and development of mammary glands begins in utero. When a heifer is born, a rudimentary mammary ductal system is present (reviewed in Rowson et al., 2012). The duct system extends from the teat cistern to the gland cistern and ends with the epithelial ducts. This epithelial tissue and its surrounding stromal elements (loose connective tissue, blood, and lymph vessels) are collectively known as mammary parenchyma (PAR). The mammary fat pad (MFP) lies adjacent to PAR and does not contain epithelial structures, only stromal elements. Mammary epithelial structures are derived from the embryonic ectoderm and stromal structures are derived from the embryonic mesoderm. Thus, any given mammary gland contains 2 major types of tissue that serve different functions. Tubulo-alveolar epithelial structures have the capacity to make and secrete milk, whereas stromal tissues primarily provide support and contribute to gland shape. 
Mammogenesis includes expansion of both PAR and MFP and occurs in embryonic, fetal, prepubertal, pubertal, and pregnant lifecycle stages, with most mammogenesis occurring during pregnancy.

Akers et al. (2005) and Meyer et al. (2006b) both note that in heifers younger than $30 \mathrm{~d}$ of age it is difficult to detect PAR and mass of PAR is typically around $150 \mathrm{mg} /$ gland. By $90 \mathrm{~d}$ of age, mass of PAR can exceed $10 \mathrm{~g} /$ gland. This represents a near 60 -fold increase in tissue mass and hints at a growth rate that far exceeds general body mass during this same period. This argues against isometric growth of PAR (with respect to body mass) and favors an allometric pattern of mammary growth in young heifers. To date, it is the general belief that an increased level of nutrient intake during the first 2 mo of age does not impair PAR growth in heifers, and may actually enhance growth (Brown et al., 2005a; Meyer et al., 2006a; Daniels et al., 2009). More research is needed on the effects of diet on PAR accretion in young heifers.

Advances in understanding potential effects of early life mammary growth (with and without nutrition program comparisons) and resultant long-term effects on PAR development and udder function have been hindered because of the need for serial slaughter data and the relatively large number of animals required to accurately evaluate mammary development over time (Brown et al., 2005a; Meyer et al., 2006a; Daniels et al., 2009). These studies have been informative; however, in each case, animals never realized lactation (Brown et al., 2005a; Meyer et al., 2006a; Daniels et al., 2009). Therefore, determination of PAR quantity and growth in young heifers in vivo would allow the same animals for longevity studies wherein milk yield is monitored in lactation.

Teat length measurement has been used in past studies as a noninvasive way to monitor mammary growth over time. Teat length increases when exogenous estrogen is administered (Moran et al., 1991; Lammers et al., 1999), and as a result, teat length has been used as a de facto bioassay to examine relative amount of circulating estrogen in prepubertal heifers. Estrogen stimulates PAR ductal elongation and branching, and is required for prepubertal mammary development (Purup et al., 1993). Work by Capuco et al. (2012) indicates that estrogen initiates paracrine signaling to promote mammary stem cell growth. Therefore, the effect that estrogen has on teat length may enable an indirect measurement of mammary epithelial cell development. However, at least one study showed no correlation between teat length and amount of secretory tissue present (Whitlock et al., 2002), potentially negating its usefulness as a noninvasive tool for measuring amount of PAR.
Manual palpation scoring of PAR has also been used as a noninvasive means of monitoring mammary growth over time. Documented ideas for how to do this were published as early as 1955, with experiments taking place in the preceding years. One example is from the doctoral studies of Donoho (1955); the use of calipers was employed as a means to measure size of PAR within each gland. It was hoped that this technique could be used to predict future milk production (Donoho, 1955). However, Donoho (1955) noted that the caliper method was difficult to perform due to amount and location of PAR within each animal. A second, perhaps more well known, example of a palpation technique was published in a Technical Bulletin by the USDA (Swett et al., 1955). The technique was established for 3- to 6-moold heifers; a relationship between palpation grade and milk yield was reported for the conditions of that experiment, but it was communicated that the procedure was not likely to be widely implemented because of the subjective nature of the evaluation, the time that it would take for the technician to be trained, and the high possibility of error (Swett et al., 1955). To illustrate the potential pitfalls of that technique in practice, a researcher in the United Kingdom attempted to use the exact technique developed by Swett et al. (1955) in a field trial that collected measurements on 727 fourmonth-old heifers (Elliot, 1957). First-lactation records were obtained for 244 of the heifers. Palpation grade at 4 mo was not correlated with first lactation milk yield (Elliot, 1957). Although the study was conclusive, the author commented that the experiment had notable limitations: the effect of nutrition was not considered and palpation scores were only obtained once before calving (Elliot, 1957). In the decades since these initial reports were published, it seems the pursuit of minimally invasive ways to monitor PAR growth fell out of favor, perhaps due in large part to technological limitations and conflicting results.

Advances in ultrasound (US) technology have enabled researchers to obtain in vivo quantitative information that has not been formerly accessible. Examination of mammary tissue by US has been previously reported in goats to examine gland cistern size (Nudda et al., 2000); dairy goats, dairy ewes, and dairy cattle to examine teat characteristics (Díaz et al., 2013, Alejandro et al., 2014, and Vetter et al., 2014, respectively); and goats to assess pathological changes of gland tissue (Fasulkov et al., 2014). Fasulkov (2012) provides a review of mammary US in ruminants. Nishimura et al. (2011) performed a single-event, nonquantitative US on Holstein heifers aged 2 to 25 mo. To our knowledge, no US experiment has been performed over time on heifers younger than 2 mo of age. The hypothesis was that 2-dimensional (2D) area of PAR, as measured by 
weekly US exams, would increase with age and may be affected by diet.

Objectives of the present study were to (1) examine the utility of US as an in vivo tool to quantify PAR cross-sectional area in Holstein heifers, assessing the potential influence of diet on PAR growth, from birth to 2 mo of age (validation measurements obtained at 2 mo of age); (2) assess relationships between weekly US measurements, teat length, manual palpation of PAR scores, and PAR mass at 2 mo of age; and (3) perform biochemical analyses on PAR and MFP excised from heifers.

\section{MATERIALS AND METHODS}

\section{Heifers and Management}

Twenty-four Holstein heifers (2 to $3 \mathrm{~d}$ old; $41 \pm 1 \mathrm{~kg}$ initial BW) were used in this experiment. Full details of the experiment are described elsewhere (Esselburn et al., 2013). Heifers were purchased from a single dairy farm in Indiana and shipped $3.5 \mathrm{~h}$ to the Nurture Research Center in New Paris, Ohio, where they were housed for the duration of the experiment. Heifers were housed and fed in $1.2 \times 2.4 \mathrm{~m}$ individual pens, bedded with long straw, within a curtain sidewall barn with no added heat. The experiment was conducted from August to October, 2011. All heifers were provided daily care following acceptable practices as described in the Guide for the Care and Use of Agricultural Animals in Research and Teaching (FASS, 2010).

Upon arrival, heifers were randomly assigned to one of 3 milk replacer (MR) diets (Esselburn et al., 2013). All MR contained 27\% CP (DM basis) and were formulated with 3 fat and FA compositions. The $3 \mathrm{MR}$ treatments were (1) only animal fat $(\mathbf{C O N}) ;(2)$ animal fat supplemented with butyrate, medium-chain FA, and linolenic acid (FA-supplemented, FA-S) using a commercial product $(1.25 \%$ NeoTec4 MR, Provimi North America, Brookville, $\mathrm{OH}$ ); and (3) milk fat (MF). Milk replacers CON and FA-S were $17 \%$ fat (DM basis) and MF was $33 \%$ fat (DM basis). All MR were diluted at $150 \mathrm{~g} / \mathrm{L}$ total volume with warm water and fed at 660 $\mathrm{g}$ of DM divided into equal a.m. and p.m. meals. On the last $3 \mathrm{~d}$ preweaning, calves were fed only their a.m. feeding and were completely weaned after $42 \mathrm{~d}$ on trial. The trial continued for an additional $14 \mathrm{~d}$ postweaning to include $56 \mathrm{~d}$ overall.

All heifers were allowed ad libitum access to water and a textured calf starter $(20 \% \mathrm{CP}$ on a DM basis; $37 \%$ whole corn, $35 \%$ supplement pellet, $25 \%$ whole oats, and 3\% molasses; supplement pellet contained $66 \%$ soybean meal, $22 \%$ wheat middlings, $9 \%$ minerals and vitamins, and 3\% molasses) through the trial.
Intake of MR and calf starter, as well as calf somatic growth data, can be found in a companion paper (Esselburn et al., 2013).

\section{Mammary Examination Procedure}

Heifers were evaluated for mammary growth by weekly teat length measurements, palpation scoring, and mammary US. On average, mammary examinations (teat length, palpation scoring, and US exam) lasted approximately 10 min per heifer.

Teat Length. Teat lengths were measured weekly by a single person; measurements were made to the nearest millimeter. Teat length measurements were obtained on all 4 glands before US evaluation.

Palpation Scores. Manual palpation of heifer PAR began at $6 \mathrm{wk}$ of age when PAR became discernible from MFP by feel. The PAR within each gland was manually palpated by a single researcher using a technique similar to that described in the 1950s (Donoho, 1955; Swett et al., 1955; Elliot, 1957). The PAR is more dense than MFP; when slight manual pressure in opposing directions is applied to a mammary gland, PAR provides more resistance to compression and thus feels harder than MFP. This tactile difference provides the basis for palpation scoring. A 6-point scale with 0.5 unit gradations was used for palpation scoring. The scale was $1=$ small and threadlike mass of PAR, comparable to a small grain of rice; $2=$ a larger grain of rice; $3=\mathrm{a}$ small pea; $4=$ a chickpea; $5=$ almond sized; $6=$ larger than an almond. Palpation exams always took place before US examination.

Mammary Ultrasound. A real-time B-mode ultrasonograph (Aloka 900, Aloka America, Wallingford, $\mathrm{CT}$ ) with a $7.5-\mathrm{MHz}$ convex probe was used to examine PAR area of all 4 glands (glands) in heifers from 0 to $2 \mathrm{~d}$ of age to $2 \mathrm{mo}$ of age. For the first 2 wk of the trial, still US images were captured using MediCapture USB170 Software (MediCapture Inc., Philadelphia, PA). Beginning at $3 \mathrm{wk}$, US videos were captured with a DVD recorder connected to the Aloka Ultrasound machine. Still images were later captured from videos using Snagit 10 (TechSmith, Okemos, MI) video processing software. Udders were not clipped of excess hair for the in vivo portion of the trial. At each exam, heifers were laid dorsally with a slight tendency to the lateral left side. They were manually restrained, and MG were consistently examined in the following order: right front, right rear, left front, and left rear. A single person performed all mammary US examinations. Ultrasound gel (Chattanooga Group Inc., Chattanooga, TN) was applied to each gland to enhance contact with the probe and the hide for optimal visualization. The probe was placed directly on top of the teat, and be- 
cause applying pressure to the teat caused it to fold, the probe was positioned so that the base of the teat would appear consistently on the right side of the US screen (Figure 1). Additionally, each teat served as a biological landmark for aid in identification of PAR via US. Because teat length was measured with a ruler before US exam, the teat could be distinguished from PAR on the US screen based on (1) proximity to US probe, and (2) length and appearance on screen. Weekly US exams were also conducted on a single bull calf as a methodological and biological control, with the expectation that gland size would not increase appreciably over time (data not shown). In all cases, PAR appeared as a dark contrast (hypoechoic feature) compared with more dorsally located hyperechoic MFP, body wall, and gastrointestinal tract, and more ventrally located hide (Figure 1).

\section{Harvest Procedure}

On October 7, 2011, heifers were trucked (2 h) from the Nurture Research Center (Provimi North America) in New Paris, Ohio, to The Ohio State University Meats Laboratory in Columbus, Ohio. Upon arrival to The Ohio State University, heifers underwent final (2 mo) mammary exams for teat length, palpation scoring, and mammary US. At this time, udders were also clipped of excess hair.

Heifers were fasted overnight and slaughtered at 0600 $\mathrm{h}$ the next day. Heifers were euthanized by captive bolt stunning followed by exsanguination. The entire udder was removed with a knife, weighed, and bisected along the medial suspensory ligament into right and left halves. Subsamples of PAR and MFP from the right half of the udder were excised and archived for future gene expression and histology analyses (data not shown).

\section{Postmortem Mammary Ultrasound}

The left udder halves were individually stored in plastic containers, temporarily stored in a cooler with ice, and transported $153 \mathrm{~km}$ to Wooster, Ohio, the same day. Containers were stored at $4^{\circ} \mathrm{C}$ overnight. The

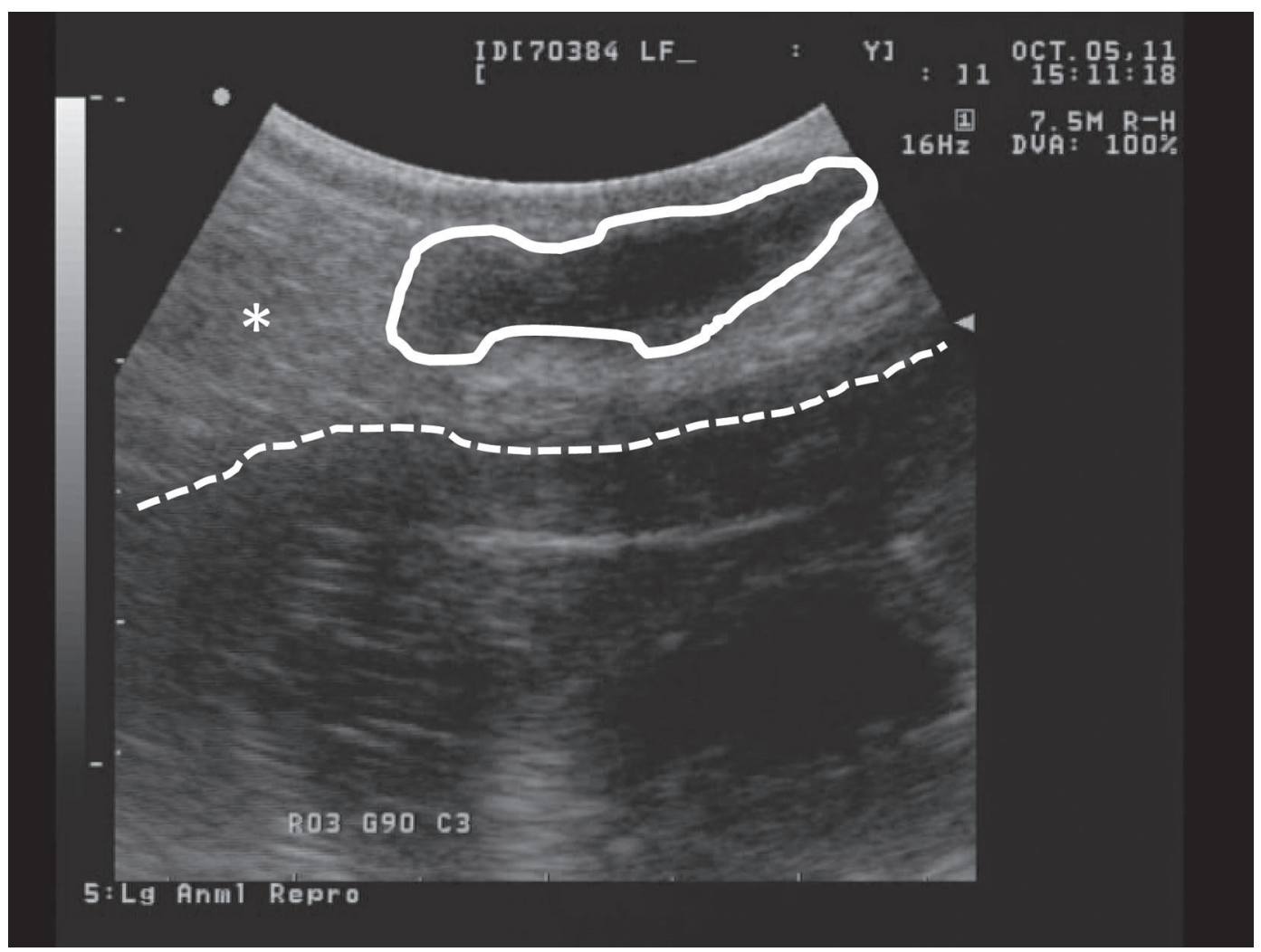

Figure 1. Eight-week antemortem mammary ultrasound (US) of one mammary gland. Mammary parenchyma is evident as a hypoechoic US feature and is circled in white; the teat is at the upper right corner. Mammary fat pad is evident as a hyperechoic US feature compared with parenchyma and is marked with an asterisk. The body wall is marked with a dashed line. White tick marks on the left vertical axis of the ultrasound screen are spaced $0.5 \mathrm{~cm}$ apart. 
next morning, left udder halves were brought to room temperature and a final US analysis was performed on both the front and rear glands. Teat location in relation to PAR on the US images was confirmed by placing a highly echogenic needle into the teat end until it reached PAR, as demonstrated in Figure 2. After the final US examination, front and rear glands were each bisected by cutting along the surface at the inserted needle to make a sagittal cut. The central mass of PAR was bisected yielding a view of the sagittal plane of PAR in each remaining gland (Figure 3). This was to correspond with US images, which also produced a sagittal view of PAR, similar to the procedure used by Nishimura et al. (2011). Digital images were then taken with a handheld camera (Nikon Coolpix S8200, Nikon Corporation, Melville, NY) with a centimeter ruler included for scale (Figure 3). After postmortem US exam, left udder halves were placed in individually labeled plastic bags and frozen at $-20^{\circ} \mathrm{C}$ for later biochemical analysis (DNA, protein, and lipid).

\section{Mammary Digital Image Processing}

Ultrasound Images. The DVDs were opened with VLC media player software (VideoLAN Organization) on a personal computer. Ultrasound playback videos were monitored and paused when PAR was fully visualized. Rapid capture of multiple images was possible with Snagit software (TechSmith) by pressing the "PrntScrn" key on the keyboard. Images were stored by Snagit and were later saved as labeled TIFF files. Images were analyzed to determine PAR area $\left(\mathrm{cm}^{2}\right)$ using the program ImageJ (National Institutes of Health; http://imagej.nih.gov/ij/index.html). The scale of pixels per cm was calibrated in ImageJ using the "straight" tracer. The tick marks on the ALOKA US images were 2 tick marks per centimeter, and when measured with ImageJ resulted in 150 pixels per centimeter. MediCapture images resulted in 130 pixels per centimeter when calibrated, which was pertinent for the first 2 wk of the trial. Once the appropriate scale was set, 2D areas were derived by tracing the PAR area with the mouse and cursor using the "freehand" tracer. Pixel area squared was converted to centimeters squared, and later to millimeters squared using the noted calibrators and conversion factors.

Bisected Tissue Images. As stated previously, left udder glands were bisected to reveal a sagittal plane view of PAR. A centimeter ruler was included in pictures of bisected tissue to assist in calibrating the scale for ImageJ. Two-dimensional PAR area was determined with the same procedure used to determine PAR area with US.

\section{Mammary Composition Analyses}

Homogenization of Tissue. At a later date, left udder halves were removed from storage at $-20^{\circ} \mathrm{C}$ and allowed to thaw for $1 \mathrm{~h}$ at $4^{\circ} \mathrm{C}$. Semi-frozen udder halves were weighed and then dissected into PAR, MFP, hide, and teats, by color. Mass of PAR was recorded on a per gland basis at dissection and then compiled for composition analysis. Mammary fat pad mass and composition analyses were performed at the level of udder half. The PAR and MFP were blended with dry ice to form powdered tissue and stored in individually labeled plastic bags at $-80^{\circ} \mathrm{C}$. These samples were used in protein, DNA, and lipid assays.

Homogenates of PAR and MFP were prepared using a Qiagen TissueLyser LT (Qiagen, Manchester, UK). Briefly, for DNA homogenates, 2-mL microcentrifuge tubes containing 1 stainless steel bead $(7 \mathrm{~mm})$ each were placed on dry ice for $15 \mathrm{~min}$. Approximately 30 $\mathrm{mg}$ of tissue was added to each tube and placed on dry ice for $15 \mathrm{~min}$. The tubes were then placed in the Qiagen TissueLyser LT Adapter for $2 \mathrm{~min}$ at room temperature. Lysis buffer (High Salt Buffer; $0.05 M$ $\mathrm{Na}_{2} \mathrm{PO}_{4}+0.002 M \mathrm{Na}_{2}$ EDTA) was added to MFP and PAR samples, 150 and $300 \mu \mathrm{L}$, respectively. Samples were homogenized in the Qiagen TissueLyser LT for 5 min at $50 \mathrm{~Hz}$, then stored at $-20^{\circ} \mathrm{C}$ until analysis in the DNA assay described below. Samples intended for use in the protein assay were homogenized as described above with PBS in place of the high salt buffer.

DNA Assay. A DNA assay was performed on homogenates using a DNA quantification kit and fluorescence assay (Sigma-Aldrich, St. Louis, MO). The bisBenzimide Hoechst 33258 dye reagent was used with calf thymus DNA as the standard. Briefly, $2 \mu \mathrm{L}$ of PAR or $10 \mu \mathrm{L}$ of MFP homogenate samples were added to 2 $\mathrm{mL}$ of assay solution. The assay solution contained 30 $\mu \mathrm{L}$ of bisBenzimide Hoechst $33258(1 \mathrm{mg} / \mathrm{mL}), 3 \mathrm{~mL}$ 10X fluorescent assay buffer, and $27 \mathrm{~mL}$ of molecular grade water. Samples were measured in triplicate on a Turn Quantech Digital Fluorometer (Barnstead/Thermolyne, Dubuque, IA) set on raw fluorescence mode at $360 \mathrm{~nm}$ excitation (NB360, Quantech, Dubuque, IA) and $460 \mathrm{~nm}$ emission (SC430, Quantech) at ambient temperature. Intraassay CV averaged $4.17 \%$ for MFP and $4.64 \%$ for PAR.

Protein Assay. Protein analysis was performed on homogenates using the Pierce BCA (bicinchoninic acid) Protein Assay Kit (Pierce Chemical Co., Rockford, IL), with BSA as the standard (Daniels et al., 2009). The MFP homogenate samples were pipetted into wells at $10 \mu \mathrm{L}$ in duplicate. The PAR homogenate samples were pipetted into wells at $2 \mu \mathrm{L}$ in duplicate. Intraassay 
A)

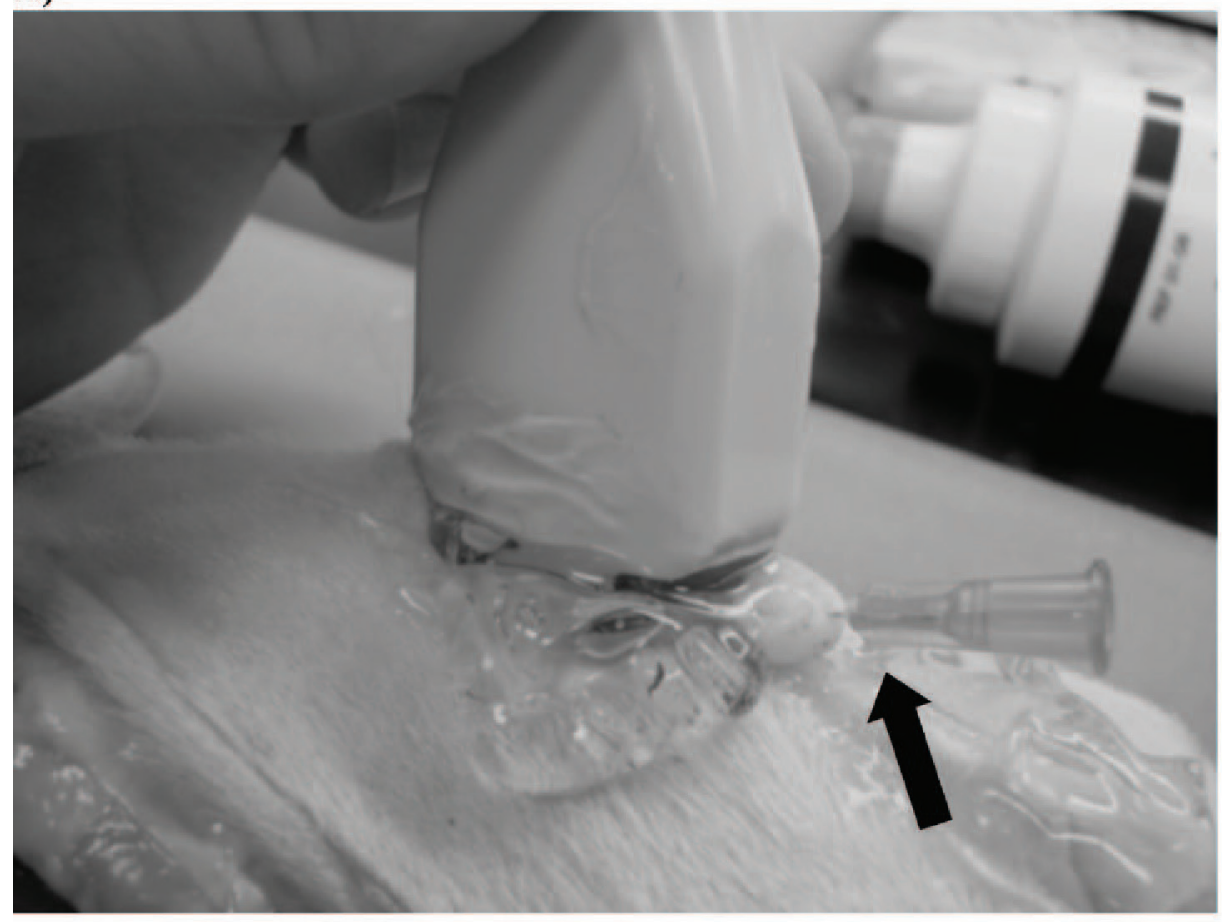

B)

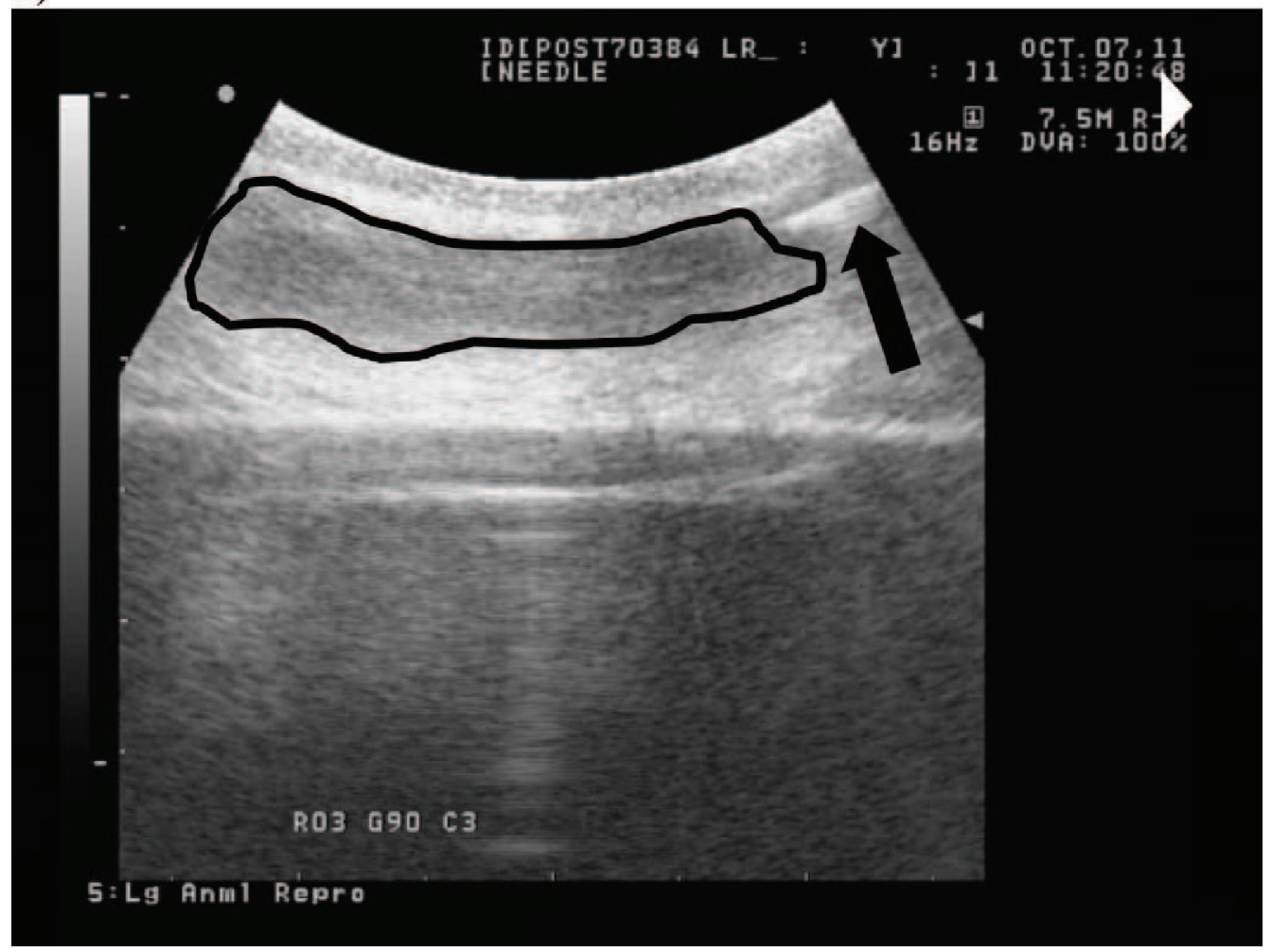

Figure 2. A) demonstration of needle placement within a teat during a postmortem mammary ultrasound (US) examination. The needle (black arrow) was used for confirmation of demarcation between teat cistern and mammary parenchyma on the US screen. B) Eight-week postmortem mammary ultrasound of one mammary gland. Upper right corner of image shows the needle (hyperechoic; white US feature) inserted into the teat (black arrow) as well as the central mass of mammary parenchyma in this gland (hypoechoic; dark US feature outlined with a solid black line). White tick marks on the left vertical axis of the ultrasound screen are spaced $0.5 \mathrm{~cm}$ apart. 


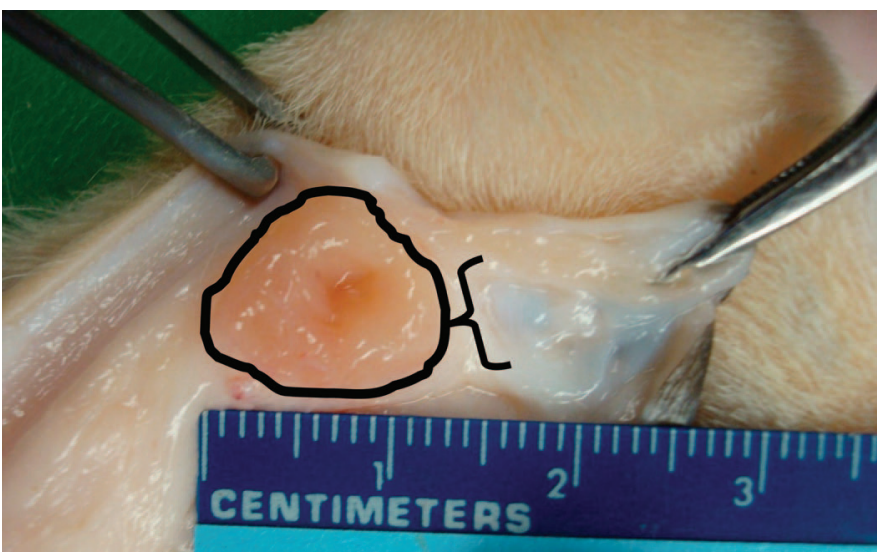

Figure 3. Image of bisected mammary parenchyma (sagittal view), showing how tissue surface area was documented in one mammary gland of an 8-wk-old heifer. Mammary parenchyma is outlined with a solid black line. Bisected teat is visible, showing teat cistern; indicated with left bracket and forceps. A centimeter ruler was included in pictures of bisected tissue to assist in calibration. Two-dimensional PAR area was determined with ImageJ software (http://imagej.nih.gov/ij/ index.html) after calibration. Color version available online.

coefficient of variation averaged $3.72 \%$ for MFP and $5.55 \%$ for PAR.

Lipid Assay. Lipid content was determined for MFP, not PAR. This was because lipid analysis as described required $1 \mathrm{~g}$ of total sample; 19 out of 24 PAR samples, representative of left front and left rear glands, had masses of less than $1 \mathrm{~g}$ of PAR. Assay linearity was checked using $1 \mathrm{~g}, 500 \mathrm{mg}, 250 \mathrm{mg}, 125 \mathrm{mg}$, and $50 \mathrm{mg}$ of starting material in duplicate. It was determined that a minimum of $250 \mathrm{mg}$ of tissue was needed for a single sample for both accuracy and precision, and duplicates would require at least $500 \mathrm{mg}$ of tissue. Fourteen of 24 PAR samples had less than $500 \mathrm{mg}$ of tissue available for this assay. The decision was made to not complete the lipid analysis for PAR samples. So, lipid content of MFP was determined by gravimetric analysis essentially according to the method of Hara and Radin (1978) as described by Daniels et al. (2009). Extraction of lipid was performed using $9 \mathrm{~mL}$ of hexane:isopropanol (3:2; $\mathrm{vol} / \mathrm{vol}$ ) added to $500 \mathrm{mg}$ of tissue powder. Samples were measured in duplicate. Average intraassay CV for MFP was $3.47 \%$.

\section{Statistical Analysis}

Heifer was the experimental unit. Weekly teat length, US, and palpation score data were analyzed using the GLIMMIX procedure of SAS (version 9.2, SAS Institute Inc., Cary, NC). A first-order autoregressive covariance structure was used for the random effect of heifer within diet; this effect tested diet. A compound symmetry covariance structure was used for the random effect of gland within heifer and diet; this effect tested gland and the interaction of diet and gland. Remaining fixed model terms included week; interaction of week and diet; interaction of week and gland; and interaction of diet, week, and gland. The residual error was assumed to be random and independently distributed. The Kenward-Rogers denominator degrees of freedom approximation method was specified for all tests.

Means for the interaction of gland and week were separated using the slice option. Main level effects were only examined if higher-order tests were not significant and main effects were. In this case, orthogonal polynomial contrasts were used to test for linear, quadratic, and cubic responses over time. Significant gland means were separated using preplanned orthogonal contrast statements for gland (front glands vs. rear glands, coded as RF and LF vs. RR and LR; and right udder half vs. left udder half, coded as RF and RR vs. LF and LR).

Mammary composition data were examined using a similar model as noted above; however, week and gland effects were removed because mammary composition data were obtained at a single time point and performed at the level of udder half (mass results multiplied by 2 for reporting purposes).

Additionally, a separate analysis containing only the 8-wk data collected on left front and left rear glands was conducted. The model for this analysis contained the fixed effects of diet, gland (left front or left rear), and the interaction of diet and gland. A first-order autoregressive covariance structure was used for the random effect of heifer within diet. The Kenward-Rogers denominator degrees of freedom approximation method was specified. Dependent variables were mode of PAR area analysis (ante- or postmortem, bisected tissue), parenchyma weight, teat length, and palpation score. The correlation procedure of SAS was used to test for linear relationships between dependent variables in the 8-wk data set.

All data are reported as least squares means \pm standard error of the mean. Significance was declared at $P$ $\leq 0.05$ for all procedures.

\section{RESULTS AND DISCUSSION}

\section{Teat Length}

Teat length was not affected by $\operatorname{diet}(P=0.283$; Table 1). Regardless of diet or gland, teat length increased over time (linear, $P=0.001$; quadratic, $P=0.001$ ). Over the course of this 8-wk trial, average teat length increased from 11 to $17 \mathrm{~mm}$ (Table 1). Teat length depended on gland. Regardless of diet or week, front glands were, on average, $1 \mathrm{~mm}$ longer than rear glands 
$(P=0.001 ;$ Table 1$)$. These results were as expected for young heifers.

\section{Palpation Scores}

A week by gland effect was observed for palpation score $(P=0.045$; Table 2$)$. An effect of diet was also noted for this variable. It should be pointed out that our palpation scale went from 1 to 6 with increments of 0.5. Data were analyzed in a continuous manner, yielding least squares means with statistical, but perhaps not biologically meaningful differences $(3.1,3.8$, and 2.9 for CON, FA-S, and MF at 8 wk, respectively), especially because this was the only dependent variable for which an effect of diet was detected. However, palpation scores were reflective of results obtained from US, meaning that although palpation scoring is subjective, we showed that one technician could effectively perform palpation exams that yielded scores coincident with weekly changes in PAR size as measured by US (discussed later).

Our observations, obtained through manual palpation, correspond with those from almost a century ago, where early postnatal PAR growth was characterized (Swett and Matthews, 1934; Swett et al., 1955). In those early studies, Swett and Matthews described early postnatal PAR as "beginning with a small tubular formation that feels like a tiny cord, leading from the teat upward toward the abdominal wall" (Swett and Matthews, 1934). They called this the "straight tube" stage of development and noted that it normally continues until the calf is at least 1 mo old, sometimes considerably longer, after which time an enlargement can be felt near the center of the straight tube, as a bulge that tapers off toward the ends (Swett and Matthews, 1934). We believe that our observations complement those from nearly a century ago and help explain why palpation scores were not recorded until 6 wk of age, when PAR likely exited the "straight tube" and entered the "enlargement stage" (Swett and Matthews, 1934).

\section{Weekly Mammary Ultrasound}

Basal tissue establishment may be a reliable indicator for developmental potential of PAR in heifers, but no reliable way is currently available to monitor PAR growth in vivo. Ultrasound is useful for external imaging of mammary glands in dairy heifers (Nishimura et al., 2011). Differences in overall composition of PAR and MFP at this stage of development allow the two to be visualized as dark and bright contrasts, respectively, with US. Nishimura et al. (2011) were able to obtain images of dairy heifers at 2 mo of age up to heifers in late pregnancy, in comparison with mammary tissue at postmortem examination. No studies to date have evaluated the growth of PAR with US in either preweaned heifers or in serial US of the same heifer over time. Weekly mammary US data are reported in Table 3. Two-dimensional PAR area was affected by the interaction of week and gland $(P=0.001)$. Diet had no effect on this variable (Table 3$)$. In general, PAR area started out small $\left(6.6 \pm 3.2 \mathrm{~mm}^{2}\right.$ per gland $)$ and increased to $42.1 \pm 2.5 \mathrm{~mm}^{2}$ per gland by the end of the trial. Using these measurements, it can be deduced that cross-sectional surface area increased increased nearly 6 fold in 2 mo. In comparison, body weight during this evaluation period did not double. This is supportive of the notion that before 2 mo of age mammary PAR growth is likely allometric and the dogmatic assumption that PAR growth is isometric during this time is not valid.

Overall, we noted a front:rear gland ratio of 47:53 by US (Table 3). A typical front:rear gland ratio in lactating cows is 40:60. Here, as expected, front glands were found to be smaller than rear glands and the ratio obtained (47:53, front:rear) seems appropriate for young heifers.

Animal to animal variation in size of PAR was high in the early weeks of this study and decreased as the study went on, as indicated by standard errors reported in Table 3. It seems that the likelihood of experiencing a type II experimental error was greatest in the youngest heifers. This may dissuade future researchers from examining young heifers, as we did, but we purposely chose the time from birth to 2 mo of age for 2 reasons. First, because heifers are typically individually housed during this time, and feasibility of working with them on a one-on-one basis is much greater when compared with postweaned, group-housed animals. Second, we chose this age due to the previous observation that level of nutrient intake in the time from birth to 2 mo of age, but not later, can affect PAR mass (Brown et al., 2005a). If diet effects had been present on PAR size in this trial, we hoped to observe them early and in vivo through weekly US analysis.

\section{8-Wk Mammary Measurements and Correlations}

Table 4 contains data collected on left udder glands during the final week of the trial. Regardless of diet, left front teats averaged $2 \mathrm{~mm}$ longer than left rear teats in wk 8 . The PAR size in left glands was measured 5 different ways in wk 8: palpation, antemortem $2 \mathrm{D}$ area by US, postmortem 2D area by US, postmortem bisected tissue surface area (by dissection), and mass. Two of these methodologies (palpation score and postmortem tissue surface area) detected smaller front compared with rear glands (Table 4), whereas no differences were 
Table 1. Average teat length per gland $(\mathrm{mm})$ for 24 Holstein heifers fed 1 of 3 diets from 0 to 8 wk of age

\begin{tabular}{|c|c|c|c|c|c|c|c|c|c|c|c|c|c|c|c|c|c|c|c|c|}
\hline \multirow[b]{3}{*}{ Week } & \multicolumn{12}{|c|}{$\operatorname{Diet}^{1}$} & \multirow[b]{3}{*}{$\mathrm{SEM}^{3}$} & \multirow{2}{*}{\multicolumn{7}{|c|}{ Test of fixed effects, $P$-value }} \\
\hline & \multicolumn{4}{|c|}{$\mathrm{CON}(\mathrm{n}=8)$} & \multicolumn{4}{|c|}{ FA-S $(\mathrm{n}=8)$} & \multicolumn{4}{|c|}{$\operatorname{MF}(\mathrm{n}=8)$} & & & & & & & & \\
\hline & $\mathrm{RF}^{2}$ & $\mathrm{RR}$ & $\mathrm{LF}$ & LR & $\mathrm{RF}$ & $\mathrm{RR}$ & LF & LR & $\mathrm{RF}$ & $\mathrm{RR}$ & $\mathrm{LF}$ & LR & & $\mathrm{D}^{4}$ & $\mathrm{~W}^{5}$ & $\mathrm{G}^{6}$ & $\mathrm{DW}^{7}$ & $\mathrm{DG}^{8}$ & $\mathrm{WG}^{9}$ & $\mathrm{DWG}^{10}$ \\
\hline Wk 0 & 12 & 11 & 12 & 11 & 11 & 10 & 10 & 9 & 12 & 11 & 12 & 11 & 1 & 0.283 & $0.001 \dagger$ & $0.001 \ddagger$ & 0.533 & 0.860 & 0.158 & 0.383 \\
\hline Wk 1 & 10 & 10 & 11 & 10 & 10 & 9 & 10 & 9 & 11 & 10 & 11 & 10 & 1 & & & & & & & \\
\hline Wk 2 & 11 & 10 & 11 & 10 & 10 & 9 & 11 & 10 & 12 & 11 & 14 & 12 & 1 & & & & & & & \\
\hline Wk 3 & 21 & 11 & 11 & 10 & 11 & 10 & 11 & 9 & 12 & 12 & 12 & 11 & 1 & & & & & & & \\
\hline Wk 4 & 12 & 11 & 13 & 11 & 13 & 11 & 13 & 11 & 15 & 14 & 15 & 13 & 1 & & & & & & & \\
\hline Wk 5 & 14 & 13 & 14 & 14 & 14 & 12 & 12 & 11 & 16 & 15 & 16 & 15 & 1 & & & & & & & \\
\hline Wk 6 & 15 & 14 & 15 & 15 & 15 & 13 & 14 & 14 & 16 & 16 & 17 & 15 & 1 & & & & & & & \\
\hline Wk 7 & 16 & 15 & 17 & 17 & 15 & 16 & 16 & 14 & 18 & 17 & 19 & 19 & 1 & & & & & & & \\
\hline Wk 8 & 15 & 16 & 17 & 16 & 16 & 16 & 17 & 16 & 18 & 17 & 19 & 16 & 1 & & & & & & & \\
\hline
\end{tabular}

${ }^{1}$ Diet: All milk replacers (DM basis) were $27 \% \mathrm{CP}$ and either $17 \%$ fat from animal fat (CON), 17\% fat from animal fat with added FA from NeoTec4 (FA-S), or 33\% fat from milk fat (MF).

${ }^{2}$ Glands were: $\mathrm{RF}=$ right front; $\mathrm{RR}=$ right rear; $\mathrm{LF}=$ left front; $\mathrm{LR}=$ left rear; measurements are in millimeters

${ }^{3} \mathrm{SEM}$ for week (8 numerator, 162.9 denominator $\mathrm{df}$ ).

${ }^{4}$ Fixed effect of diet (CON, FA-S, MF).

${ }^{5}$ Fixed effect of week (0 to 8$)$.

${ }^{6}$ Fixed effect of gland (RF, RR, LF, LR).

${ }^{7}$ Fixed interaction of diet and week.

${ }^{8}$ Fixed interaction of diet and gland.

${ }^{9}$ Fixed interaction of week and gland.

${ }^{10}$ Fixed interaction of diet, week, and gland.

$\dagger$ Linear effect of week $(P=0.001)$; quadratic effect of week $(P=0.039)$.

$\ddagger \mathrm{RF}$ and $\mathrm{LF}$ versus $\mathrm{RR}$ and $\mathrm{LR}(P=0.001) ; \mathrm{RF}$ and $\mathrm{RR}$ versus $\mathrm{LF}$ and $\mathrm{LR}(P=0.001)$. 
Table 2. Average palpation scores ${ }^{1}$ presented by diet, ${ }^{2}$ gland, ${ }^{3}$ and week of the trial for 24 Holstein heifers fed 1 of 3 diets from 0 to 8 wk of age

\begin{tabular}{|c|c|c|c|c|c|c|c|c|c|c|c|c|c|c|c|c|c|c|c|c|}
\hline \multirow[b]{3}{*}{ Week } & \multicolumn{12}{|c|}{ Diet } & \multirow[b]{3}{*}{$\mathrm{SEM}^{4}$} & & & & & & & \\
\hline & \multicolumn{4}{|c|}{$\mathrm{CON}(\mathrm{n}=8)$} & \multicolumn{4}{|c|}{ FA-S $(\mathrm{n}=8)$} & \multicolumn{4}{|c|}{$\operatorname{MF}(\mathrm{n}=8)$} & & \multicolumn{7}{|c|}{ Test of fixed effects, $P$-value } \\
\hline & $\mathrm{RF}$ & $\mathrm{RR}$ & $\mathrm{LF}$ & $\mathrm{LR}$ & $\mathrm{RF}$ & $\mathrm{RR}$ & $\mathrm{LF}$ & LR & $\mathrm{RF}$ & $\mathrm{RR}$ & $\mathrm{LF}$ & $\mathrm{LR}$ & & $\mathrm{D}^{5}$ & $\mathrm{~W}^{6}$ & $\mathrm{G}^{7}$ & $\mathrm{DW}^{8}$ & $\mathrm{DG}^{9}$ & $\mathrm{WG}^{10}$ & $\mathrm{DWG}^{11}$ \\
\hline Wk 6 & 2.5 & 2.8 & 2.5 & 2.8 & 2.6 & 3.0 & 2.5 & 2.9 & 2.1 & 2.3 & 2.1 & 2.4 & 0.27 & 0.001 & 0.781 & 0.001 & 0.999 & 0.950 & 0.045 & 0.992 \\
\hline Wk 7 & 2.6 & 3.1 & 2.5 & 3.1 & 2.9 & 3.3 & 3.0 & 3.3 & 2.1 & 2.5 & 2.1 & 2.5 & 0.27 & & & & & & & \\
\hline Wk 8 & 2.8 & 3.7 & 2.8 & 3.7 & 3.4 & 4.2 & 3.4 & 4.2 & 2.6 & 3.2 & 2.6 & 3.2 & 0.27 & & & & & & & \\
\hline
\end{tabular}

${ }^{1}$ Palpation scores were only obtained during wk 6 to 8 of the trial. Palpation scores were graded on a 1 to 6 scale by a single observer. The scale was $1=$ small and threadlike mass of PAR, comparable to a small grain of rice; $2=$ a larger grain of rice; $3=$ a small pea; $4=$ a chickpea; $5=$ almond sized; $6=$ larger than an almond.

${ }^{2}$ Diet: All milk replacers (DM basis) were $27 \% \mathrm{CP}$ and either $17 \%$ fat from animal fat (CON), 17\% fat from animal fat with added FA from NeoTec4 (FA-S), or 33\% fat from milk fat $(\mathrm{MF})$.

${ }^{3}$ Glands were: $\mathrm{RF}=$ right front; $\mathrm{RR}=$ right rear; $\mathrm{LF}=$ left front; $\mathrm{LR}=$ left rear

${ }^{4} \mathrm{SEM}$ for week (2 numerator, 35.5 denominator df).

${ }^{5}$ Fixed effect of diet (CON, FA-S, MF).

${ }^{6}$ Fixed effect of week (6 to 8$)$

${ }^{7}$ Fixed effect of gland (RF, RR, LF, LR).

${ }^{8}$ Fixed interaction of diet and week.

${ }^{9}$ Fixed interaction of diet and gland.

${ }^{10}$ Fixed interaction of week and gland.

${ }^{11}$ Fixed interaction of diet, week, and gland.

Table 3. Average parenchyma (PAR) area $\left(\mathrm{mm}^{2} /\right.$ gland) from 0 to 8 wk of age, in heifers fed 1 of 3 diets, as measured by mammary ultrasound

\begin{tabular}{|c|c|c|c|c|c|c|c|c|c|c|c|c|c|c|c|c|c|c|c|c|}
\hline \multirow[b]{3}{*}{ Week } & \multicolumn{12}{|c|}{$\operatorname{Diet}^{1}$} & \multirow[b]{3}{*}{$\mathrm{SEM}^{2}$} & & & & & & & \\
\hline & \multicolumn{4}{|c|}{$\mathrm{CON}(\mathrm{n}=8)$} & \multicolumn{4}{|c|}{ FA-S $(\mathrm{n}=8)$} & \multicolumn{4}{|c|}{$\mathrm{MF}(\mathrm{n}=8)$} & & \multicolumn{7}{|c|}{ Test of fixed effects, $P$-value } \\
\hline & $\mathrm{RF}$ & $\mathrm{RR}$ & $\mathrm{LF}$ & $\mathrm{LR}$ & $\mathrm{RF}$ & $\mathrm{RR}$ & $\mathrm{LF}$ & $\mathrm{LR}$ & $\mathrm{RF}$ & $\mathrm{RR}$ & $\mathrm{LF}$ & LR & & $\mathrm{D}^{3}$ & $\mathrm{~W}^{4}$ & $\mathrm{G}^{5}$ & $\mathrm{DW}^{6}$ & $\mathrm{DG}^{7}$ & $\mathrm{WG}^{8}$ & $\mathrm{DWG}^{9}$ \\
\hline Wk 0 & 5.0 & 6.0 & 7.4 & 7.5 & 8.8 & 7.0 & 6.1 & 6.0 & 7.3 & 5.3 & 6.1 & 6.9 & 3.20 & 0.944 & 0.001 & 0.001 & 0.995 & 0.261 & 0.001 & 0.469 \\
\hline Wk 1 & 9.0 & 7.3 & 7.3 & 7.8 & 11.1 & 8.6 & 7.9 & 8.8 & 7.4 & 9.0 & 7.9 & 6.5 & 2.57 & & & & & & & \\
\hline Wk 2 & 10.8 & 10.3 & 11.8 & 9.9 & 11.4 & 11.5 & 11.1 & 10.0 & 9.6 & 11.0 & 11.4 & 11.2 & 2.59 & & & & & & & \\
\hline Wk 3 & 12.2 & 15.0 & 14.2 & 15.3 & 12.9 & 12.4 & 10.7 & 10.9 & 13.6 & 12.7 & 11.4 & 14.4 & 2.58 & & & & & & & \\
\hline Wk 4 & 19.9 & 19.5 & 15.5 & 15.4 & 19.5 & 13.7 & 15.3 & 18.1 & 16.6 & 16.9 & 16.2 & 16.1 & 2.57 & & & & & & & \\
\hline Wk 5 & 15.7 & 17.6 & 19.6 & 19.6 & 12.6 & 17.0 & 19.6 & 20.1 & 14.0 & 18.3 & 21.7 & 18.0 & 2.57 & & & & & & & \\
\hline Wk 6 & 25.4 & 25.0 & 20.6 & 23.7 & 26.2 & 32.1 & 20.8 & 30.1 & 22.7 & 30.2 & 29.2 & 34.9 & 2.57 & & & & & & & \\
\hline Wk 7 & 25.5 & 29.0 & 29.0 & 32.2 & 29.5 & 34.9 & 17.1 & 34.0 & 31.4 & 29.8 & 31.2 & 34.0 & 2.57 & & & & & & & \\
\hline Wk 8 & 32.1 & 45.5 & 34.2 & 42.4 & 32.8 & 53.4 & 38.3 & 47.5 & 41.5 & 48.2 & 42.4 & 46.8 & 2.57 & & & & & & & \\
\hline
\end{tabular}

Diet: All milk replacers (DM basis) were $27 \%$ CP and either $17 \%$ fat from animal fat (CON), $17 \%$ fat from animal fat with added FA from NeoTec4 (FA-S; Provimi North America, Brookville, $\mathrm{OH}$ ), or $33 \%$ fat from milk fat (MF).

( ${ }^{2}$ SEM for week (8 numerator, 151 denominator $\mathrm{df}$ ).

$\delta \quad{ }^{3}$ Fixed effect of diet (CON, FA-S, MF).

${ }^{4}$ Fixed effect of week $(0$ to 8$)$

${ }^{5}$ Fixed effect of gland (RF, RR, LF, LR).

Z $\quad{ }^{6}$ Fixed interaction of diet and week.

$\infty \quad{ }^{7}$ Fixed interaction of diet and gland.

$\sim \quad{ }^{8}$ Fixed interaction of week and gland.

$\vec{c}{ }^{9}$ Fixed interaction of diet, week, and gland. 
Table 4. Least squares means and standard errors for measurements obtained at 8 wk of age on left udder halves [left front (LF) and left rear (LR) glands] of 24 Holstein heifers fed 1 of $3 \operatorname{diets}^{1}$

\begin{tabular}{|c|c|c|c|c|c|c|c|c|c|c|}
\hline Item & \multicolumn{6}{|c|}{$\operatorname{Diet}^{2}$} & $\mathrm{SEM}^{3}$ & & & \\
\hline 8 wk teat length, mm & 19 & 18 & 16 & 14 & 18 & 15 & 3 & 0.856 & 0.001 & 0.258 \\
\hline 8 wk palpation score $(1$ to 6$)$ & 3.3 & 4.1 & 2.5 & 3.0 & 2.8 & 3.8 & 0.8 & 0.747 & 0.001 & 0.617 \\
\hline $8 \mathrm{wk}$ antemortem US, $\mathrm{mm}^{2}$ & 35.1 & 43.2 & 36.3 & 45.4 & 42.6 & 47.0 & 13.6 & 0.954 & 0.691 & 0.862 \\
\hline 8 wk PAR, mg & 271 & 303 & 239 & 404 & 507 & 378 & 208 & 0.900 & 0.736 & 0.203 \\
\hline
\end{tabular}

${ }^{1}$ Data include summary of teat length, manual palpation score, antemortem ultrasound (US), postmortem US, postmortem tissue surface measurement, and mammary parenchyma (PAR) mass.

${ }^{2}$ Diet: All milk replacers (DM basis) were $27 \% \mathrm{CP}$ and either $17 \%$ fat from animal fat (CON), $17 \%$ fat from animal fat with added FA from NeoTec4 (FA-S; Provimi North America, Brookville, OH), or $33 \%$ fat from milk fat (MF).

${ }^{3} \mathrm{SEM}=$ standard error of the mean for diet $\times$ gland; highest listed $(2$ numerator, 21 denominator $\mathrm{df})$.

${ }^{4}$ Fixed effect of diet (CON, FA-S, MF).

${ }^{5}$ Fixed effect of gland (LF, LR).

${ }^{6}$ Fixed interaction of diet and gland.

detected via the other 3 modes of analysis. No diet effects were detected in the data set containing only 8-wk data on left udder glands. On average, antemortem US area measurements were $76 \%$ of postmortem bisected tissue surface area for the same gland. Postmortem values were $84 \%$ of postmortem bisected tissue surface area, and antemortem US values were $90 \%$ of postmortem US values for the same gland (Table 4). Noted differences between ante- and postmortem measurements could have various causes. (1) Tissue may have changed properties to some extent during overnight storage; (2) we had more physical control over the half udders upon dissection (as opposed to in vivo) and could therefore maneuver them more easily, perhaps indicating better overall contact with the US probe; (3) udders were clipped of excess hair before the postmortem exam, which could also have led to better contact with the US probe.

Of the 15 correlation coefficients returned in our association analysis, 13 coefficients were significant
(Table 5). The strongest positive linear relationship existed between postmortem US and PAR mass $(\mathrm{r}=$ $0.805 ; P=0.001)$. Importantly for this trial, at $8 \mathrm{wk}$, antemortem US had a positive correlation to PAR mass $(\mathrm{r}=0.74 ; P=0.001)$. No statistical relationships were found to exist between antemortem US and teat length $(\mathrm{r}=0.23)$, or tissue surface area and teat length $(\mathrm{r}=$ $0.34)$.

As hoped, it seems that in vivo US might be a better tool to assess amount of PAR $(\mathrm{r}=0.74 ; P=0.001)$ than either teat length $(\mathrm{r}=0.34 ; P=0.01)$ or palpation scoring $(\mathrm{r}=0.63 ; P=0.001)$, and it has the benefit of being quantitative. It should however be noted that in this experiment, all 3 of these variables (antemortem US, palpation score, and teat length) were positively related to mass of PAR at 2 mo; however, the strongest relationship however was between antemortem US and PAR mass.

Although we only validated our US measurements at 8 wk, given the strong correlation between PAR area

Table 5. Correlation coefficients between: ante- and postmortem ultrasound (US) measurements, tissue surface area measurement, mammary parenchyma (PAR) tissue mass, teat length, and palpation scores on left front and left rear glands for 8-wk-old Holstein heifers ${ }^{1}$

\begin{tabular}{lccccc}
\hline Item & $\begin{array}{c}\text { Postmortem } \\
\text { US }\end{array}$ & $\begin{array}{c}\text { Tissue surface } \\
\text { area }\end{array}$ & $\begin{array}{c}\text { PAR } \\
\text { mass }\end{array}$ & $\begin{array}{c}\text { Teat } \\
\text { length }\end{array}$ & $\begin{array}{c}\text { Palpation } \\
\text { score }\end{array}$ \\
\hline Antemortem US & $0.705 \ddagger$ & $0.618 \ddagger$ & $0.741 \ddagger$ & $0.230^{\mathrm{NS}}$ & $0.684 \ddagger$ \\
Postmortem US & & $0.731 \ddagger$ & $0.805 \ddagger$ & $0.383 \dagger$ & $0.766 \ddagger$ \\
Tissue surface area & & $0.632 \ddagger$ & $0.203^{\mathrm{NS}}$ & $0.664 \ddagger$ \\
PAR mass & & & $0.341 \dagger$ & $0.630 \ddagger$ \\
Teat length & & & & $0.356 \dagger$ \\
\hline
\end{tabular}

${ }^{1}$ Pearson correlation coefficients, $\mathrm{n}=48$.

$\dagger P \leq 0.01 . \ddagger P \leq 0.001$. 
and mass at 8 wk $(\mathrm{r}=0.74 ; P=0.001)$, we feel our US measurements obtained in vivo from wk 1 through 8 precisely, and perhaps to a lesser extent accurately, reflect how PAR cross-sectional area grew over time. It is not lost on the authors that we may be able to use our US data to retrospectively predict PAR volume and mass in a given week of the experiment if a constant PAR density is assumed and rules of Galileo's squarecube law are obeyed. This is a distinct advantage of US over either palpation scoring or teat length measurements. Further evaluation of these data will also allow us to address questions about isometric and allometric scaling of PAR area, volume, or mass over time as animals increase in BW.

\section{PAR and MFP Composition}

Heifers were provided 1 of $3 \mathrm{MR}$ diets differing in fat source and concentration, whereas protein concentration was consistent across diets. The PAR and MFP of the MG were evaluated for protein and DNA content. Additionally, MFP was evaluated for lipid content (total amounts of PAR tissue were insufficient to complete the lipid assay in heifers at 8 wk of age). In previous work by Daniels et al. (2009), no effect of MR composition was observed on PAR size or composition, whereas total MFP lipid and MFP lipid concentration were influenced by diet. Meyer et al. (2006b) performed an analysis of MFP and PAR content when heifers were harvested at $50-\mathrm{kg}$ increments up to $350 \mathrm{~kg}$ of $\mathrm{BW}$, and found differences in PAR DNA content; the first age of harvest was 2.7 mo. They concluded that nutrient intake did not affect PAR composition, but age at harvest influenced total PAR DNA content. Brown et al. (2005a) also observed increased amount of PAR and PAR DNA due to increased dietary protein and energy in 2- to 8-wk-old heifers.

In this study, neither PAR nor MFP composition (DNA, protein, lipid) differed due to diet (Table 6). Also, total mammary mass, as well as quantity of MFP and PAR tissue, was much lower compared with results from heifers in the aforementioned studies, at 2 mo of age, despite being of similar final BW $(71.73 \pm 1.64$ $\mathrm{kg}$ here; $80.65 \pm 1.23 \mathrm{~kg}$ in Daniels et al. (2009); 66.05 $\pm 1.5 \mathrm{~kg}$ in Brown et al. (2005b); average final BW \pm SEM). This study had only $18.3 \%$ as much PAR (g of PAR/100 kg of EBW) as Daniels et al. (2009), and $51.9 \%$ as much PAR as Brown et al. (2005a). It is

Table 6. Total mammary parenchyma (PAR) and fat pad (MFP) mass and composition for heifers fed 1 of 3 milk replacer diets; analyzed at 8 wk of age ${ }^{1}$

\begin{tabular}{|c|c|c|c|c|c|}
\hline \multirow[b]{2}{*}{ Item } & \multicolumn{3}{|c|}{ Diet $^{2}$} & \multirow[b]{2}{*}{$\mathrm{SEM}^{3}$} & \multirow{2}{*}{$\begin{array}{c}\text { Fixed effect } \\
\text { of diet, } \\
P=\end{array}$} \\
\hline & $\begin{array}{c}\mathrm{CON} \\
(\mathrm{n}=8)\end{array}$ & $\begin{array}{c}\text { FA-S } \\
(\mathrm{n}=8)\end{array}$ & $\begin{array}{c}\text { MF } \\
(\mathrm{n}=8)\end{array}$ & & \\
\hline \multicolumn{6}{|l|}{ PAR } \\
\hline Mass, $\mathrm{g}$ & 1.15 & 1.28 & 1.77 & 0.80 & 0.900 \\
\hline Mass, g/100 kg of empty BW & 1.70 & 2.18 & 2.84 & 1.29 & 0.863 \\
\hline Lipid, ${ }^{4}$ mg/g PAR & - & - & - & - & - \\
\hline Total lipid, ${ }^{4} \mathrm{~g}$ & - & - & - & - & - \\
\hline Protein, $\mathrm{mg} / \mathrm{g}$ of PAR & 86.31 & 90.76 & 87.81 & 5.7 & 0.863 \\
\hline Total protein, $\mathrm{g}$ & 0.10 & 0.15 & 0.16 & 0.06 & 0.721 \\
\hline $\mathrm{DNA}, \mathrm{mg} / \mathrm{g}$ of PAR & 4.29 & 5.02 & 5.27 & 1.63 & 0.635 \\
\hline Total DNA, mg & 6.58 & 4.32 & 9.70 & 4.11 & 0.681 \\
\hline \multicolumn{6}{|l|}{ MFP } \\
\hline Mass, $\mathrm{g}$ & 66.42 & 65.44 & 69.99 & 11.21 & 0.955 \\
\hline Mass, g/100 kg of empty BW & 103.35 & 104.38 & 112.52 & 17.03 & 0.918 \\
\hline Lipid, mg/g of MFP & 428.6 & 424.5 & 403.5 & 5.9 & 0.950 \\
\hline Total lipid, g & 31.17 & 30.67 & 34.00 & 8.85 & 0.959 \\
\hline Protein, mg/g of MFP & 24.89 & 30.21 & 24.32 & 5.32 & 0.723 \\
\hline Total protein, g & 1.54 & 1.83 & 1.59 & 0.20 & 0.590 \\
\hline $\mathrm{DNA}, \mathrm{mg} / \mathrm{g}$ of $\mathrm{MFP}$ & 1.42 & 1.36 & 1.35 & 0.25 & 0.967 \\
\hline Total DNA, mg & 77.37 & 78.97 & 73.86 & 5.29 & 0.761 \\
\hline \multicolumn{6}{|l|}{ Total udder } \\
\hline Mass, $\mathrm{g}$ & 68.98 & 68.00 & 72.55 & 11.21 & 0.955 \\
\hline Mass, g/100 kg of empty BW & 114.42 & 104.62 & 115.35 & 15.61 & 0.868 \\
\hline
\end{tabular}

${ }^{1}$ Tabular values represent left hemi-udder values $\times 2$.

${ }^{2}$ Diet: All milk replacers (DM basis) were $27 \% \mathrm{CP}$ and either $17 \%$ fat from animal fat (CON), $17 \%$ fat from animal fat with added FA from NeoTec4 (FA-S; Provimi North America, Brookville, OH), or 33\% fat from milk fat (MF).

${ }^{3} \mathrm{SEM}$ for $\operatorname{diet}(\mathrm{n}=8)$.

${ }^{4}$ Lipid content in PAR was not determined due to small sample size. 
possible that genetics contribute to observed differences in PAR tissue presence. At 2 mo of age, it is clear that drastic differences in PAR presence can occur in dairy heifers; more research is needed to determine the influence of basal tissue differences on future milk yield.

\section{CONCLUSIONS}

The first objective was to examine the utility of US as an in vivo tool to quantify PAR area in Holstein heifers reared on 1 of 3 experimental diets from birth to 2 mo of age (validation measurements obtained at 2 mo of age). It was hypothesized that $2 \mathrm{D}$ area of PAR, as measured by weekly US exams, would increase with age and may be affected by diet. We did not observe an effect of on cross-sectional area in the present study; however, the use of US to quantify weekly growth of PAR was documented in the present study. A second objective was to perform a correlation analysis between weekly US measurements, teat length, manual palpation of PAR scores, and PAR mass at 2 mo of age. As hoped, it seems that in vivo US is a usable tool to assess amount of PAR and has quantitative advantages over teat length measurements and palpation scoring. The final objective was to perform biochemical analyses on PAR and MFP excised from heifers reared on 1 of 3 experimental diets. Diet did not affect mass, protein, or DNA content of PAR (lipid content not measured) in young heifers. In conclusion, we showed that in heifers younger than 2 mo of age, obtaining weekly PAR measurements via US is an effective quantitative tool for measuring changes in PAR area in vivo. Future studies may incorporate and expand upon the methods developed here to determine what quantitative evaluation of PAR can reveal about milk production capacity. One important caveat that scientists should consider when planning future studies is that although US appears to be useful in young heifers, as the amount of PAR increases such that the boundaries can no longer be visualized in one field of view on the US screen, the utility of US for measuring amount of PAR will likely decrease.

\section{ACKNOWLEDGMENTS}

The authors thank the staff at the Provimi Nurture Center for their role in animal care and feeding and $\mathrm{R}$. L. Schlotterbeck (Provimi North America) for project oversight. This work was partially funded by Provimi North America, Brookville, Ohio. Gratitude is expressed to A. Ottobre, M. Chakerian, and M. Day at The Ohio State University for assistance with ultrasound equipment; V. Swank for assistance with animal handling during ultrasound; and H. Zerby along with the staff at the Meat Science Laboratory for their assistance with animal processing and tissue collection.

\section{REFERENCES}

Akers, R. M., S. E. Ellis, and S. D. Berry. 2005. Ovarian and IGFI axis control of mammary development in prepubertal heifers. Domest. Anim. Endocrinol. 29:259-267.

Alejandro, M., M. Rodríguez, C. Peris, and J. R. Díaz. 2014. Study of ultrasound scanning as method to estimate changes in teat thickness due to machine milking in Manchega ewes. Small Rumin. Res. 119:138-145.

Brown, E. G., M. J. VandeHaar, K. M. Daniels, J. S. Liesman, L. T. Chapin, J. W. Forrest, R. M. Akers, R. E. Pearson, and M. S. W. Nielsen. 2005a. Effect of increasing energy and protein intake on mammary development in heifer calves. J. Dairy Sci. 88:595-603.

Brown, E. G., M. J. VandeHaar, K. M. Daniels, J. S. Liesman, L. T. Chapin, D. H. Keisler, and M. S. W. Nielsen. 2005b. Effect of increasing energy and protein intake on body growth and carcass composition of heifer calves. J. Dairy Sci. 88:585-594.

Capuco, A. V., R. K. Choudhary, K. M. Daniels, R. W. Li, and C. M. Evock-Clover. 2012. Bovine mammary stem cells: Cell biology meets production agriculture. Animal 6:382-393.

Daniels, K. M., A. V. Capuco, M. L. McGilliard, R. E. James, and R. M. Akers. 2009. Effects of milk replacer formulation on measures of mammary growth and composition in Holstein heifers. J. Dairy Sci. 92:5937-5950.

Díaz, J. R., M. Alejandro, C. Peris, and N. Fernández. 2013. Use of ultrasound scanning to estimate teat wall thickness in MurcianoGranadina goats. Livest. Sci. 155:114-122.

Donoho, H. R. 1955. The association of immature bovine udder evaluations and subsequent milk and butterfat productions. PhD Thesis. The Ohio State University, Columbus, $\mathrm{OH}$.

Elliot, G. M. 1957. Mammary gland development in the calf as a possible predictor of subsequent milk production. J. Dairy Res. 24:162-164.

Esselburn, K. M., K. M. O’Diam, T. M. Hill, H. G. Bateman, J. M. Aldrich, R. L. Schlotterbeck, and K. M. Daniels. 2013. Intake of specific fatty acids and fat alters growth, health, and titers following vaccination in dairy calves. J. Dairy Sci. 96:5826-5835.

FASS. 2010. Guidelines for the Care and Use of Agricultural Animals in Research and Teaching. 3rd ed. Federation of Animal Science Societies, Champaign, IL.

Fasulkov, I., P. Georgiev, A. Wehrend, and S. Goericke-Pesch. 2014. Ultrasonographic findings of pathological changes in the mammary gland in Bulgarian native goats. Small Rumin. Res. 120:174-180.

Fasulkov, I. R. 2012. Ultrasonography of the mammary gland in ruminants: A review. Bulgarian J. Vet. Med. 15:1-12.

Hara, A., and N. S. Radin. 1978. Lipid extraction of tissues with a low-toxicity solvent. Anal. Biochem. 90:420-426.

Lammers, B. P., A. J. Heinrichs, and R. S. Kensinger. 1999. The effects of accelerated growth rates and estrogen implants in prepubertal Holstein heifers on estimates of mammary development and subsequent reproduction and milk production. J. Dairy Sci. $82: 1753-1764$.

Meyer, M. J., A. V. Capuco, Y. R. Boisclair, and M. E. Van Amburgh. 2006a. Estrogen-dependent responses of the mammary fat pad in prepubertal dairy heifers. J. Endocrinol. 190:819-827.

Meyer, M. J., A. V. Capuco, D. A. Ross, L. M. Lintault, and M. E. Van Amburgh. 2006b. Developmental and nutritional regulation of the prepubertal heifer mammary gland: I. Parenchyma and fat pad mass and composition. J. Dairy Sci. 89:4289-4297.

Moran, C., J. F. Quirke, D. J. Prendiville, S. Bourke, and J. F. Roche. 1991. The effect of estradiol, trenbolone acetate, or zeranol on growth-rate, mammary development, carcass traits, and plasma estradiol concentrations of beef heifers. J. Anim. Sci. 69:42494258 . 
Nishimura, M., T. Yoshida, S. El-Khodery, M. Miyoshi, H. Furuoka, J. Yasuda, and K. Miyahara. 2011. Ultrasound imaging of mammary glands in dairy heifers at different stages of growth. J. Vet. Med. Sci. 73:19-24.

Nudda, A., G. Pulina, R. Vallebella, R. Bencini, and G. Enne. 2000. Ultrasound technique for measuring mammary cistern size of dairy ewes. J. Dairy Res. 67:101-106.

Purup, S., K. Sejrsen, J. Foldager, and R. M. Akers. 1993. Effect of exogenous bovine growth-hormone and ovariectomy on prepubertal mammary growth, serum hormones and acute in vitro proliferative response of mammary explants from Holstein heifers. J. Endocrinol. 139:19-26.

Rowson, A. R., K. M. Daniels, S. E. Ellis, and R. C. Hovey. 2012 Growth and development of the mammary glands of livestock: A veritable barnyard of opportunities. Semin. Cell Dev. Biol. 23:557-566.
Swett, W. W., J. H. Book, C. A. Matthews, and M. H. Fohrman. 1955. Evaluation of mammary-gland development in Holstein and Jersey calves as a measure of potential producing capacity. USDA Technical Bull. No. 1111:1-44

Swett, W. W., and C. A. Matthews. 1934. Dairy cow's udder studied to establish developmental standards. Yearbook of Agriculture; USDA, Washington, DC.

Vetter, A. H., A. van Dorland, M. Youssef, and R. M. Bruckmaier. 2014. Effects of a latency period between pre-stimulation and teat cup attachment and periodic vacuum reduction on milking characteristics and teat condition in dairy cows. J. Dairy Res. 81:107-112.

Whitlock, B. K., M. J. VandeHaar, L. F. P. Silva, and H. A. Tucker 2002. Effect of dietary protein on prepubertal mammary development in rapidly growing dairy heifers. J. Dairy Sci. 85:1516-1525. 